\title{
BMJ Open Menstrual hygiene management among Bangladeshi adolescent schoolgirls and risk factors affecting school absence: results from a cross-sectional survey
}

\author{
Mahbub-Ul Alam, ${ }^{1}$ Stephen P Luby, ${ }^{1,2}$ Amal K Halder, ${ }^{1}$ Khairul Islam, ${ }^{3}$ Aftab Opel, ${ }^{3}$ \\ Abul K Shoab, ${ }^{1}$ Probir K Ghosh, ${ }^{1}$ Mahbubur Rahman, ${ }^{1}$ Therese Mahon, ${ }^{4}$ \\ Leanne Unicomb ${ }^{1}$
}

To cite: Alam M-U, Luby SP, Halder AK, et al. Menstrual hygiene management among Bangladeshi adolescent schoolgirls and risk factors affecting school absence: results from a crosssectional survey. BMJ Open 2017;7:e015508. doi:10.1136/ bmjopen-2016-015508

- Prepublication history and additional material for this paper are available online. To view these files please visit the journal online (http://dx.doi. org/10.1136/bmjopen-2016015508).

Received 9 December 2016 Revised 8 May 2017 Accepted 10 May 2017

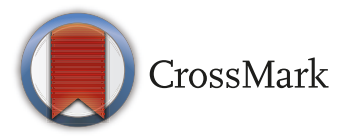

${ }^{1}$ Environmental Interventions Unit, Infectious Disease Division, International Center for Diarrheal Disease Research, Dhaka, Bangladesh

${ }^{2}$ Stanford Woods Institute for the Environment, Stanford University, Stanford, California, USA

${ }^{3}$ WaterAid Bangladesh, Dhaka, Bangladesh

${ }^{4}$ WaterAid, London, UK

Correspondence to Mahbub-UI Alam; mahbubalam@icddrb.org, mahbubanthro@gmail.com

\section{ABSTRACT}

Background Many adolescent girls in low-income and middle-income countries lack appropriate facilities and support in school to manage menstruation. Little research has been conducted on how menstruation affects school absence. This study examines the association of menstrual hygiene management knowledge, facilities and practice with absence from school during menstruation among Bangladeshi schoolgirls.

Methods We conducted a nationally representative, cross-sectional study in Bangladeshi schools from March to June 2013 among girls 11 to 17 years old who reached menarche. We sampled 700 schools from 50 urban and 50 rural clusters using a probability proportional to size technique. We interviewed 2332 schoolgirls and conducted spot checks in each school for menstrual hygiene facilities. To assess factors associated with reported school absence, we estimated adjusted prevalence difference (APD) for controlling confounders' effect using generalised estimating equations to account for school-level clustering.

Results Among schoolgirls who reached menarche, $41 \%$ (931) reported missing school, an average of 2.8 missed days per menstrual cycle. Students who felt uncomfortable at school during menstruation $(99 \%$ vs $32 \%$; $\mathrm{APD}=58 \%$; $\mathrm{Cl} 54$ to 63 ) and who believed menstrual problems interfere with school performance (64\% vs $30 \%$; $A P D=27 ; \mathrm{Cl} 20$ to 33) were more likely to miss school during menstruation than those who did not. School absence during menstruation was less common among girls attending schools with unlocked toilet for girls $(35 \%$ vs $43 \% ; \mathrm{APD}=-5.4 ; \mathrm{Cl}-10$ to -1.6$)$. School absence was more common among girls who were forbidden from any activities during menstruation ( $41 \%$ vs $33 \% ; A P D=9.1 ; \mathrm{Cl}$ 3.3 to 14$)$.

Conclusion Risk factors for school absence included girl's attitude, misconceptions about menstruation, insufficient and inadequate facilities at school, and family restriction. Enabling girls to manage menstruation at school by providing knowledge and management methods prior to menarche, privacy and a positive social environment around menstrual issues has the potential to benefit students by reducing school absence.
Strengths and limitations of this study

- We attempted to quantify the complex ways by which menstruation affects girls at school.

- We conducted a nationally representative, crosssectional study in Bangladeshi schools and interviewed 2332 students from 700 schools.

- We used a sampling weight to determine national estimates that might over-represent small schools.

- With the help of female teachers at school, we identified adolescent schoolgirls who reached menarche, and so our sample might be nonrepresentative because teachers might be more likely to have suggested including girls who have difficulty with menstruation.

\section{BACKGROUND}

Menstrual hygiene management (MHM) at school is constrained by poor access to water and sanitation, lack of privacy and limited education about menstrual hygiene ${ }^{1}$ as well as social stigma and cultural restrictions on activities. ${ }^{2}$ Menstruation poses a set of physical, sociocultural and economic challenges to adolescent girls that may interfere with their ability to attend school or to participate fully in classroom. ${ }^{3}$

Girls' education has a long-term positive impact on personal welfare and health as well as economic and social development, especially in low-income communities. ${ }^{4}$ Better-educated women are more likely to be healthier than uneducated women, participate more in the formal labour market, earn higher incomes, get married at a later age and have fewer children, potentially ensuring better health status and education for their children ${ }^{5}$ that can reduce poverty and contribute to a country's development. However, a number of small-scale, mostly qualitative studies have found that many 
school-age girls do not attend school during menstruation $^{26-8}$ due to shame, fear of having visible stains on their clothing, absence of a private place to manage menstruation in school ${ }^{27910}$ or dysmenorrhoea. ${ }^{11} 12$ In an Ethiopian study, about $90 \%$ of girls stated that their academic performance or class rank declined after menarche. ${ }^{7}$ However, little attempt has been made to quantify the complex ways by which menstruation affects girls at school. ${ }^{13}$ The present study measured school absence reported by students and used this to quantify its relationship with MHM.

Barriers to MHM among Bangladeshi girls may hamper progress towards Sustainable Development Goals 3 (ensure healthy lives and well-being for all at all ages), 4 (ensure inclusive and equitable quality education and promote lifelong learning opportunities for all), 5 (promote gender equality and empower all women and girls) and 6 (ensure the availability and sustainable management of water and sanitation for all). ${ }^{14}$ This study aims to describe the current state of MHM among students from Bangladeshi schools and examine the association between menstrual hygiene knowledge, facilities and practice and absence from school during menstruation.

\section{METHODS}

\section{Study design and school sampling}

We conducted a national, cross-sectional study in Bangladeshi schools from March to June 2013 among girls who had reached menarche and were enrolled in grades 2 to 9 as part of a study to examine water, sanitation and hygiene facilities, knowledge and practices. ${ }^{15}$ We used probability proportional to size sampling to select 50 rural villages and 50 urban areas as clusters so that we would have sufficient power across the national hygiene survey to compare rural and urban prevalence. For the selection of rural clusters, we used the National Population and Housing Census 2011 data, ${ }^{16}$ and for the urban sampling frame, we used the 2006 Urban Health Survey data $^{17}$ as primary data from the National Population and Housing Census 2011 on the urban area were not available during the design phase of our study.

As part of the Bangladesh National Hygiene Baseline Survey, ${ }^{15}$ we determined the sample size required to estimate the national coverage of handwashing with soap in school. We assumed $80 \%$ power, and $\alpha$ of 0.05 with a design effect of 12 , and based our calculations on the indicator 'schools having soap and water at handwashing location' from a recent rural schools survey. ${ }^{18} \mathrm{We}$ assumed a $10 \%$ difference in this indicator between rural and urban schools and estimated that 672 schools would be required to measure this difference. We sampled the seven government and non-government schools, at both primary and secondary level, nearest to the midpoint of each cluster and thus selected 700 schools.

\section{Selection of participants}

Field staff asked female teachers to mark on the attendance registry which of the girls present in school on the day of the survey had reached menarche. Students had to seek permission from teachers before leaving school due to any urgent matter and usually girls inform female teachers about issues related to menstruation. The field staff then numbered the eligible girls and used a random number generator to select four of these girls from grades 2 to 5 in primary schools and from grades 6 to 9 in secondary schools to take the survey. If any students selected from the register were not interested in participating in the survey, the team interviewed those who consented and then continued to the next school.

\section{Data collection}

Trained female data collectors conducted facility spot checks then administered the survey verbally and recorded responses using a computer tablet-based structured questionnaire. Visits to schools were unannounced and surveys were conducted after obtaining informed consent from the school authority. During spot checks, the team looked for menstrual hygiene facilities, particularly the presence and type of toilet, the presence of soap inside or within $10 \mathrm{~m}$ of the toilet, presence of water and a disposal bin inside the toilet, and whether the door was unlocked from the outside and therefore accessible to students. We designed data collection instruments during group discussions with all stakeholders and included questions to collect data on variables reported in published studies of menstrual hygiene. ${ }^{213}$ 19-21

The girls were asked if they missed class during their last three menstrual cycles, the average number of days they were absent per cycle during their last three cycles and whether they thought MHM problems impacted school performance. Finally, we reviewed the national education curriculum for grades 2 to 9 to understand the current menstrual hygiene education syllabus and textbook material.

\section{Outcome and exposures}

The primary outcome variable was reported average number of school absence days in the last three menstrual cycles. The interviewer asked girls 'Did you miss any class during menstruation in the last threemonths?' If the respondents answered yes, the interviewer asked 'how often (average of last three months in school days)?' The girls' attitude and knowledge about menstruation, reason for school absence during menstruation and practices related to menstruation were collected by asking openended, multiple-choice questions. The interviewer coded the response into categories with an option for other if an appropriate category was not listed. The full questionnaire is included as online supplementary file.

\section{Statistical analysis}

We conducted statistical analysis according to a predefined conceptual model (figure 1) that reflected our hypothesis 


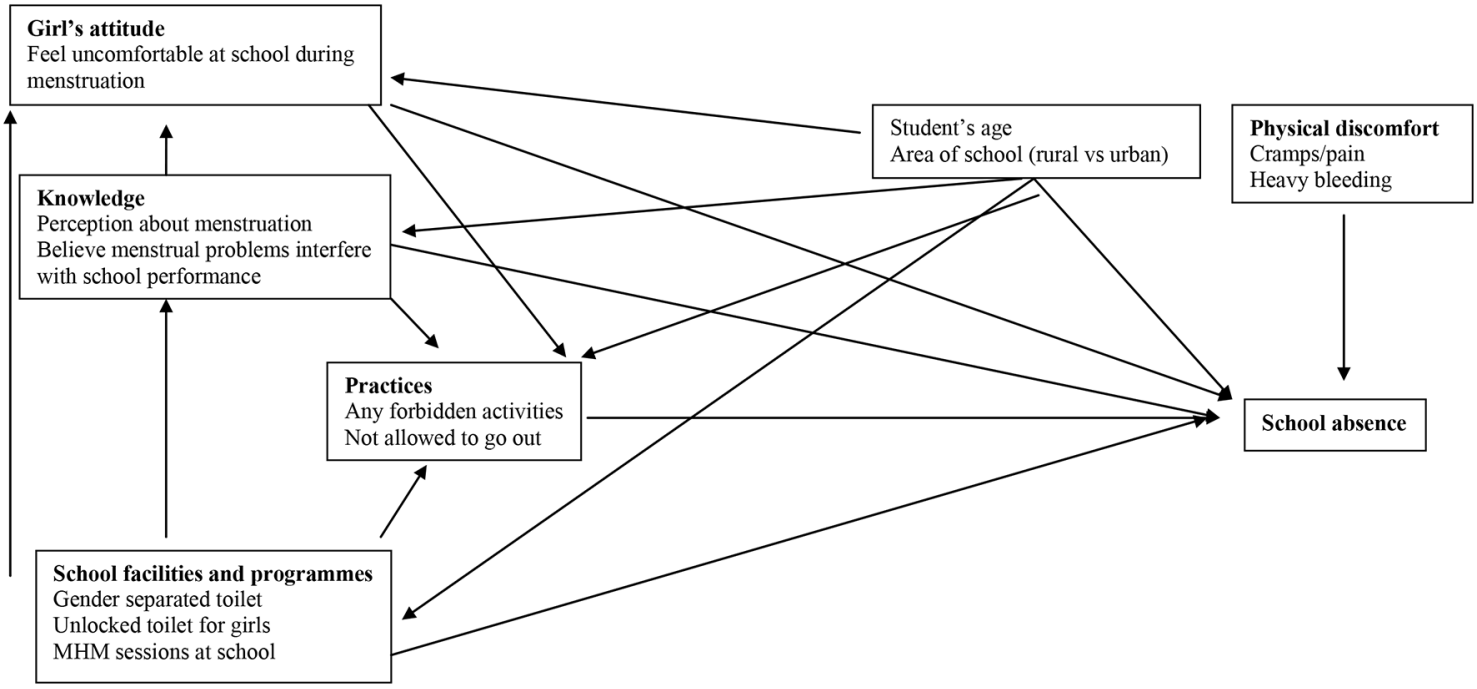

Figure 1 Conceptual framework for school absence during menstruation among schoolgirls where exposures were categorised in four blocks for school absence outcome: (1) girl's attitude, (2) knowledge, (3) school facilities and programmes, and (4) practices. Student's age and area of school were considered as confounder. Physical discomfort could be directly linked with school absence. MHM, menstrual hygiene management.

about how school absence could be affected by a range of factors. First, we performed descriptive analysis to determine student characteristics, students' attitude and knowledge about menstruation, school facilities and programmes for MHM, and students' menstrual hygiene practice. We reported means and SD for continuous variables that were normally distributed. Because we used a probability proportional to size technique to select clusters among 86925 rural clusters and 10552 urban clusters, we used a sampling weight to calculate national estimates adjusting for rural/urban balance, calculated as $\mathrm{f}=1 / \mathrm{F}$, where $\mathrm{F}$ is the total number of urban or rural clusters. We also weighted for school size to calculate national estimates, calculated as $s=1 / \mathrm{S}$, where $\mathrm{S}$ is the total number of the students in the school. All percentages and means reported are weighted national estimates.

We calculated the prevalence difference for school absence among school students for our exposures of interest using generalised estimating equations with robust standard errors to account for school-level clustering and adjust overdispersion. Exposures were grouped in four blocks by following the conceptual model: (1) attitude, (2) knowledge, (3) school facilities and programmes, and (4) practices. We performed bivariate analysis between exposures and outcome to calculate crude association. We further considered only those exposures associated with outcomes with a $\mathrm{p}<0.2$. We then conducted multivariable analysis among the exposures within each block including confounders identified in the conceptual model. We retained exposure within each block associated with outcome at the $\mathrm{p}<0.05$ level. We then built an overall multivariate model by using exposure variables from each block that were associated with school absence at the $\mathrm{p}<0.05$ level and that captured most of the measurement. We identified 'feel uncomfortable at school during menstruation' variable from girl's attitude block, 'believe menstrual problems interfere with school performance' variable from knowledge block, 'gender-separated unlocked toilet for girls at school' variable from school facilities block and 'forbidden from any activities during menstruation' variable from practice block for overall multivariable analysis. We calculated the adjusted prevalence difference (APD) for the outcome with the exposures of interest identified in the previous step by controlling for potential confounders identified in the conceptual model. We identified the student's age and area of the school (rural or urban) as confounders, as we would expect these factors to be associated with menstruation-related attitude, knowledge, facilities and practices as well as predict school absence (figure 1).

We used the WHO/Unicef Joint Monitoring Programme definitions for improved water source and improved toilet. ${ }^{22}$ We defined a toilet as 'functional' if students could use it on the day of the survey, if it had a working door and if it was lockable from the inside with a latch. We calculated the 'school year' based on the academic calendar for primary and secondary schools of Bangladesh, with weekends and holidays excluded.

\section{Ethical consideration}

The data collectors obtained informed verbal assent from participants and informed written consent from their guardians as well as the consent of the head teacher. We obtained approval from icddr,b's Ethical Review Committee and the Policy Support Unit of the Ministry of Local Government.

\section{RESULTS}

\section{School and student characteristics}

Seventy-six per cent of schools included in the study were primary schools and $24 \%$ were secondary. Primary schools 
Table 1 Characteristics of Bangladeshi schools and girl students, 2013

\begin{tabular}{|c|c|c|c|}
\hline Indicators & $\mathrm{n} / \mathrm{N}$ & $\% *$ or mean (SD) & $95 \% \mathrm{Cl}$ \\
\hline \multicolumn{4}{|l|}{ Type of school by grade level: } \\
\hline Primary & $511 / 700$ & 76 & (73 to 80$)$ \\
\hline \multicolumn{4}{|l|}{ Type of school by management: } \\
\hline Government & $466 / 700$ & 67 & (64 to 70$)$ \\
\hline \multicolumn{4}{|l|}{ Mean no of students per school } \\
\hline Primary & $n=511$ & $310(288)$ & - \\
\hline Secondary & $n=189$ & 559 (389) & - \\
\hline \multicolumn{4}{|l|}{ Female teacher present at school: } \\
\hline Primary & $2419 / 3297$ & 61 & (57 to 65$)$ \\
\hline Mean grade level of respondents & $n=2332$ & $6(1.6)$ & - \\
\hline Mean age at menarche (years) & $n=2326$ & $11.9(0.9)$ & - \\
\hline
\end{tabular}

*Weighted percentage for rural/urban balance and school size.

had an average of 310 students and secondary schools 559. In primary schools, $61 \%$ of teachers were women whereas in secondary schools only $22 \%$ of teachers were women. The mean age of interviewed girls was 13 among 2332 participants. Average age at menarche was 12 (table 1) and $98 \%$ of students started menstruation before age 14 .

\section{Knowledge, attitude, facilities and practices}

Sixty-four per cent of girls reported they had no knowledge of menstruation before reaching menarche. Twenty-six per cent of girls received information on menstruation prior to menarche from their female relatives before menarche and $<1 \%$ from their teachers. Thirty-two per cent of respondents stated that menstrual problems interfered with school performance. Only $9 \%$ of girls reported that schools provided menstrual hygiene education sessions for girls. On average, schools provided menstrual hygiene education sessions at grade 8 , when girls were around 14 years old (table 2 ).

Textbooks addressed some issues related to adolescence, that is, what is puberty, when it starts and what happens after this. However, the menstrual hygiene content mainly described menstruation as a biological process and did not provide practical information about how to manage changes to girls' bodies.

Eighty-two per cent of girls judged school facilities as inappropriate for managing menstrual hygiene. Eighty-two per cent of schools had an improved toilet for girls, but only $28 \%$ of schools had one or more improved toilet that was unlocked from the outside and therefore accessible to students. Thus, $54 \%$ of schools did not have an improved, unlocked toilet that students could access and only $9 \%$ of schools among all had a toilet with soap and water inside. Thirty-one per cent of schools had a designated private unlocked toilet or change room to change menstrual materials. Among the schools that had a private unlocked toilet, there were a mean of 98 girls for each toilet.

Eighty-six per cent of girls used cloth during menstruation; $10 \%$ used disposable pads. Girls attending urban schools were more likely to use disposable pads (urban: 21\%, rural: 9\%, APD: 12; CI 8.1 to 16 ). Among cloth users, $64 \%$ washed their cloths with soap. Only 3\% of girls washed their cloths with soap, dried them in sunlight and stored them with other cloth for repeated use, which is identified as the best cloth cleansing practice in the Bangladesh National Hygiene Promotion Strategy. ${ }^{23}$ Eighty-six per cent of girls reported that they did not change their menstrual cloth during school hours, which spanned approximately 4 hours for primary schools and 7 hours for secondary schools. School students reported family-imposed restrictions during menstruation: $71 \%$ reported that they were 'not allowed to go out/to certain places', $51 \%$ reported that they were 'not allowed to perform religious activities', 32\% reported that they were 'not allowed to cook/eat certain food' and $7 \%$ reported that they were 'instructed not to walk fast' during menstruation (table 2).

\section{School absence}

Forty-one per cent of girls reported missing school during menstruation, 42\% (449/1106) in rural schools and $38 \%(482 / 1226)$ in urban schools. Absentee girls missed an average of 2.8 days each menstrual cycle, constituting approximately $16 \%$ of the academic year. When asked why they missed school, 59\% reported that they felt uncomfortable sitting beside boys during menstruation, $31 \%$ reported that they felt embarrassed at school during menstruation, $5 \%$ reported that there was no place to change menstrual materials in school 
Table 2 Menstrual hygiene knowledge, practices and school facilities for Bangladeshi schoolgirls, 2013

\begin{tabular}{|c|c|c|c|}
\hline Indicators & $\mathrm{n} / \mathrm{N}$ & $\begin{array}{l}\text { \%* or mean } \\
\text { (SD) }\end{array}$ & $95 \% \mathrm{Cl}$ \\
\hline \multicolumn{4}{|l|}{ Current perception about menstruation: } \\
\hline No idea & $1132 / 2332$ & 49 & (44 to 55$)$ \\
\hline A normal biological process for women & $959 / 2332$ & 40 & (34 to 45$)$ \\
\hline A female illness & $229 / 2332$ & 10 & (7 to 14$)$ \\
\hline Curse of God & $12 / 2332$ & 1 & (0.1 to 1$)$ \\
\hline Knew/heard about menstruation before menarche & $862 / 2332$ & 36 & (33 to 39) \\
\hline \multicolumn{4}{|l|}{ Knew/heard about menstruation issues before menarche from: } \\
\hline Mother/sister/aunt/grandmother & $592 / 2332$ & 26 & (23 to 29 ) \\
\hline Friend & $255 / 2332$ & 11 & (8 to 14$)$ \\
\hline Teacher & $15 / 2332$ & 0.64 & $(0.32$ to 0.91$)$ \\
\hline Believe menstrual problems interfere with school performance & $756 / 2332$ & 32 & (27 to 37$)$ \\
\hline \multicolumn{4}{|l|}{ Materials used during menstruation: } \\
\hline Re-used cloth & $1904 / 2332$ & 86 & (84 to 88$)$ \\
\hline Disposable pad & $355 / 2332$ & 10 & (8.5 to 12$)$ \\
\hline Othert & $43 / 2332$ & 2 & (1.2 to 3$)$ \\
\hline Mean no of menstrual cloth changes per day & $\mathrm{n}=1898$ & $3(1)$ & \\
\hline Washed cloth with soap and improved water source for repeated use & $1225 / 1904$ & 57 & (50 to 63$)$ \\
\hline $\begin{array}{l}\text { Washed cloth with soap and improved source of water and dried in } \\
\text { sunlight for repeated use }\end{array}$ & $525 / 1904$ & 25 & (21 to 29$)$ \\
\hline School has a place $\neq$ to change menstrual materials & $733 / 2332$ & 31 & (27 to 35$)$ \\
\hline Schools with separate improved toilet for girls & $602 / 700$ & 82 & \\
\hline Schools with separate improved and unlocked toilet for girls & $671 / 2332$ & 28 & (24 to 33$)$ \\
\hline Mean no of female students per improved and unlocked toilet for girls & $\mathrm{n}=363$ & $98(48)$ & - \\
\hline School has improved toilet with soap and water available & $213 / 2332$ & 9 & (6.9 to 12$)$ \\
\hline $\begin{array}{l}\text { Perceived that school facilities were inappropriate for managing } \\
\text { menstrual hygiene }\end{array}$ & $1906 / 2332$ & 82 & (77 to 88$)$ \\
\hline \multicolumn{4}{|l|}{ Disposal location of absorbent materials at school: } \\
\hline Did not change and dispose at school & $1935 / 2332$ & 83 & (79 to 86$)$ \\
\hline Inside toilet pan & $85 / 2332$ & 4 & (2.6 to 4.8$)$ \\
\hline Hidden inside classroom & $73 / 2332$ & 3 & (1.8 to 4.6$)$ \\
\hline In the open & $71 / 2332$ & 3 & (2 to 4$)$ \\
\hline Menstrual hygiene education session had ever been provided at school & $213 / 2332$ & 9 & $(6.8$ to 11$)$ \\
\hline $\begin{array}{l}\text { Mean grade level for which menstrual hygiene education sessions were } \\
\text { provided at school }\end{array}$ & $\mathrm{n}=213$ & $8(1.7)$ & \\
\hline \multicolumn{4}{|l|}{ Family enforced prohibitions during menstruation: } \\
\hline Not allowed to go out/to certain places & $1096 / 2332$ & 71 & (68 to 74$)$ \\
\hline Not allowed to perform religious activities & $1185 / 2332$ & 54 & (49 to 60$)$ \\
\hline Not allowed to cook/eat certain food & $741 / 2332$ & 32 & (29 to 34$)$ \\
\hline No restriction & $362 / 2332$ & 16 & $(13$ to 19$)$ \\
\hline Instructed not to walk fast/run & $160 / 2332$ & 7 & (5 to 8$)$ \\
\hline
\end{tabular}

*Weighted for rural/urban balance and school size.

†Cotton/tissue paper/waste fabrics from garment factories.

fUnlocked toilet for girls or change room. 


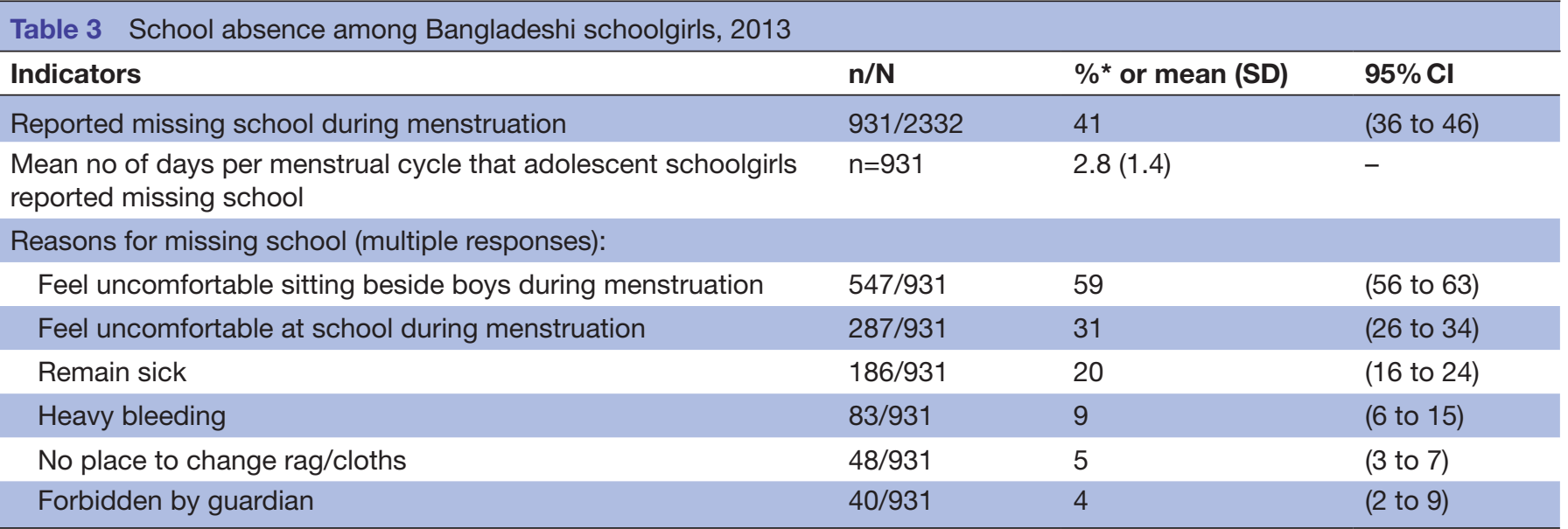

*Weighted percentage for rural/urban balance and school size.

and $4 \%$ said their guardians forbade them to go to school (table 3).

After controlling for confounders, school absence during menstruation was more common among girls who felt uncomfortable at school during menstruation $(99 \%$ vs $32 \%$; $\mathrm{APD}=58 \%$; CI 54 to 63 ) and who perceived MHM interferes with school performance than who did not (64\% vs 30\%; APD=27; CI 20 to 33) (table 4).

School absence during menstruation was less common among girls where the schools had an unlocked or open gender-separated toilet for girls than when toilet was found locked and unavailable to girls during the spot check ( $35 \%$ vs $43 \%$; APD $=-5.4$; CI -10 to -1.6$)$. Girls who were forbidden from any activities during menstruation were more likely to miss schools $(41 \%$ vs $33 \%$; APD $=9.1$; CI 3.3 to 14) compared with those who did not face such restrictions (table 4).

Girls who used cloth that was washed with water only or washed with soap and not dried in sunlight were just as likely to miss school compared with girls who used pads ( $42 \%$ vs $40 \%$; $\mathrm{APD}=-2.1$; CI -9.1 to 5.1 ) or who used cloth washed with soap and water and dried in sunlight $(42 \%$ vs $38 \%$; $\mathrm{APD}=-4.4$; $\mathrm{CI}-12$ to 3.4 ).

\section{DISCUSSION}

In a nationally representative sample of school children across Bangladesh, $41 \%$ of girls post-menarche reported usually missing school during menstruation. ${ }^{26}$ Assuming the number of days reported missed by the study subject is accurate, we estimated they were absent for $16 \%$ of the school year, a quantity of missed classroom work that would be expected to substantially impact school performance. $^{26}$ In our study, school absence during menstruation was independently associated with negative attitudes and perceptions about menstruation, not having a gender-separated unlocked toilet for girls at schools and being forbidden from activities during menstruation, factors that are similar to other studies. ${ }^{79} 1021$ 24-27

Other studies have noted marked difficulties in measuring school attendance. ${ }^{1320} 28$ In some qualitative studies, girls reported missing school because of menstruation, ${ }^{269}$ but when investigators attempted to quantify this effect systematically, they have not always replicated these findings. ${ }^{28-30}$ Attendance is difficult to measure. Schools are often compensated based on the number of students enrolled, so there is a strong incentive to over-report attendance on routine monitoring, thus making official records invalid measures. ${ }^{31}$ Various investigators have used different approaches to address this issue, including diaries of girls ${ }^{2832}$ and assessing attendance by study personnel on unannounced visits. ${ }^{32}$ It is also difficult to attribute absence to menstruation. Girls might be unwilling to mention menstruation as a reason they missed school because of stigma associated with menstruation. ${ }^{629}$ Girls also may leave school early and miss hours of a school day due to menstruation, which would not be counted as absence. ${ }^{21}$

Nevertheless, several studies support the idea that menstruation affects attendance. Multiple intervention trials that have improved facilities for menstrual hygiene have measurably improved girls' attendance. ${ }^{27}{ }^{31-37}$ In Bangladesh, a 6-month educational intervention among 416 girl students aged 11-16 years from three schools demonstrated a $31 \%$ increase in students' knowledge about menstruation and a $5.1 \%$ decrease in self-reported school absence among participants from baseline. ${ }^{35}$ In Ghana, a menstrual hygiene education programme increased girls' school attendance where attendance data were collected from teachers' register book, by around 6 days per 65 days term (9\% of a girl's school year). ${ }^{32}$ A study conducted in Kenyan schools found that toilet access was more effective in reducing absence among girls than among boys due to its impact on MHM. ${ }^{31}$

Not all studies have found a convincing relationship between menstruation and absenteeism. Oster and Thornton collected daily data on school attendance and menstrual calendars, and found that menstruation had only limited impact on school attendance. ${ }^{20}$ That study included 198 schoolgirls from seventh and eighth grade of four schools, and the mean age of girls was 14.2 years, which was 1.4 years older than our surveyed girls. At the beginning of menarche, girls may miss more school days 
Table 4 Factors associated with school absence during menstruation among Bangladeshi schoolgirls, 2013

\section{Absent during}

menstruation PD† APD

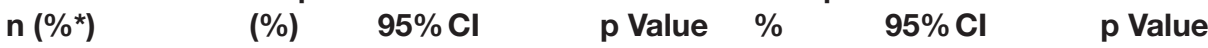

$\begin{aligned} & \text { Feel uncomfortable at school during } \\ & \text { menstruation }\end{aligned}$
$\begin{array}{lllllll}\text { Yes } & 284 / 287(99) & 66 & (61 \text { to } 71) & 0.000 & 58 & 54 \text { to } 63 \\ \text { No } & 647 / 2045(32) & - & - & - & - & -\end{array}$

Current perception about

menstruation:

$\begin{array}{lllllll}\text { A normal biological process } & 357 / 959(38) & - & - & - & - & - \\ \text { No idea } & 455 / 1132(40) & 0.5 & (-5.7 \text { to } 6.7) & 0.998 & - & - \\ \text { A female illness } & 115 / 229(52) & 10 & (0.2 \text { to 18) } & 0.015 & - & -\end{array}$

Believe menstrual problems interfere

with school performance

$\begin{array}{llllllll}\text { Yes } & 480 / 756(64) & 36 & (29 \text { to } 44) & 0.000 & 27 & (20 \text { to } 33) & <0.001 \\ \text { No } & 451 / 1576(30) & - & - & - & - & - \\ \text { Gender-separated toilet at school } & & & & & \\ \text { Yes } & 400 / 1036(36) & -5.0 & (-11 \text { to } 0.5) & 0.075 & - & - \\ \text { No } & 531 / 1296(43) & - & - & - & - & -\end{array}$

Gender-separated unlocked toilet for

girls at school

\begin{tabular}{|c|c|c|c|c|c|c|c|}
\hline Yes & $355 / 945$ (35) & -5.5 & $(-11$ to -0.5$)$ & 0.039 & -5.4 & $(-10$ to -1.6$)$ & 0.049 \\
\hline No & $576 / 1387(43)$ & - & - & - & - & - & \\
\hline \multicolumn{8}{|c|}{$\begin{array}{l}\text { School provided menstrual hygiene } \\
\text { education session for girls }\end{array}$} \\
\hline Yes & $72 / 213(40)$ & -1.5 & $(-11$ to 14$)$ & 0.816 & - & - & \\
\hline No & $859 / 2119(42)$ & - & - & - & - & - & \\
\hline
\end{tabular}

Forbidden from any activities during menstruation

\begin{tabular}{llllllll} 
Yes & $801 / 1970(41)$ & 10 & $(2.3$ to 18) & 0.011 & 9.1 & $(3.3$ to 14$)$ & 0.008 \\
$\quad$ No & $130 / 362(33)$ & - & - & - & - & - & \\
$\begin{array}{l}\text { Not allowed to go out during } \\
\text { menstruation }\end{array}$ & & & & & & & \\
Yes & $263 / 604(46)$ & 5.9 & $(-0.6$ to 12) & 0.076 & - & - \\
No & $668 / 1728(38)$ & - & - & - & - & - \\
\hline
\end{tabular}

*Weighted percentage for rural/urban balance and school size.

†Prevalence difference.

$\ddagger$ Adjusted prevalence difference calculated by adjusting for 'feel uncomfortable at school during menstruation', 'believe menstrual problems interfere with school performance', 'unlocked toilet for girls at school', 'student's age' and 'area of school (rural vs urban).

as they may not have fully developed strategies for coping with menstruation. ${ }^{20} 38$ An intervention trial providing a menstrual cup or sanitary pads compared with puberty and hygiene training was unable to measure evidence of impact on school absence among girls receiving the menstrual cup or pads. ${ }^{30}$ This study, however, only enrolled schools with gender-specific girls' toilet, while in our study we found the absence of an available gender-specific toilet was one reason for school absence during menstruation. In addition, puberty and hygiene training may also have better prepared schoolgirls to manage menstruation in the control schools.
The $41 \%$ absence rate during menstruation in our study was higher than that reported in a smaller-scale study in Maharashtra, India, where data were collected using a pre-tested, self-administered structured questionnaire among girls aged $10-19$ years (561 girls, $14 \%$ absent), ${ }^{11}$ but similar to those reported in Habru, Ethiopia ( 595 girls, $55 \%$ absent), ${ }^{7}$ and West Bengal, India (190 girls, 39\% absent), ${ }^{39}$ that also used a self-administered questionnaire for collecting school absence data. Considering both the global experience as well as local context within Bangladesh, we consider the self-report of Bangladeshi schoolgirls in our survey to be a credible assessment of their experience. 
Girls were more likely to report absence from school if they also reported negative attitudes about menstruation, such as perceiving it as something unhealthy, shameful or obstructive to learning. Such attitudes may arise from the prevalent patriarchal culture in the society, ${ }^{26}$ and that around two-thirds of girls did not know about menstruation before they reached menarche. Some studies reported that girls who did not receive any information about menstruation before menarche were more stigmatised about menstruation contributing to a culture of shame among them. ${ }^{40-42}$ Increasing the knowledge and changing attitudes about menstruation among adolescent schoolgirls in Pakistan increased girls' confidence to manage menstruation hygienically. ${ }^{43}$

This study identified several weaknesses in the current school curriculum on menstruation. The strict biological focus of school textbooks provided no opportunity for constructive discussion of healthy attitudes ${ }^{44}$ or salient social and religious issues. Moreover, teaching reproductive health is not mandated by the government. Even where schools had some course material on menstruation, $91 \%$ of girls reported that they had never received menstrual hygiene education sessions at school. Students who did receive formal education sessions usually participated in such classes after commencing menstruation. Less than $1 \%$ of students cited school teachers as a source of information regarding menstruation. Our study suggests several reasons why schools in Bangladesh provide so little useful education on menstruation. First, the national education curriculum and textbooks do not address the important social and cultural issues regarding menstruation. Second, the lack of timely information contributes to poor menstrual hygiene practices ${ }^{45}$ and increased risk of urinary tract infection. ${ }^{46}$ Third, only $22 \%$ of secondary school teachers are women in Bangladesh, compared with $61 \%$ of primary school teachers. Girls may not feel comfortable discussing menstruation with men. ${ }^{26} 4546$ Improving menstrual education to Bangladeshi girls requires two steps: first, schools and the education board need to be persuaded to consider menstrual hygiene as part of their educational mission. Second, the timing, content and delivery of the menstrual curriculum need to be revised to better address the needs of girls.

Lack of a gender-separated improved accessible or open toilet at school for girls was another reason for the absence. In Bangladesh, the number of girls per toilet was two times higher than the national recommended standard of 50 girls per toilet. ${ }^{23}$ Simply ensuring that toilets in schools are unlocked from the outside may increase the number of accessible toilets for girls as more than half of the separate toilets for girls were locked when the study team visited during school hours. In our study, lack of gender-separated open toilets was associated with missing school, similar to a finding in a recent systematic review ${ }^{34}$ suggesting that simply ensuring gender-separated toilets for girls to change menstrual materials is important. Studies from other countries also report similar findings. ${ }^{27} 32333637$ A study from India reported that $28 \%$ of girls missed school during menstruation due to lack of facilities ${ }^{36}$ and in Nepal, $41 \%$ of students reported a lack of privacy for cleaning and washing as a major reason for absence during menstruation. ${ }^{27}$ In Ghana, girls missed school due to inadequate sanitation facilities at school during menstruation. ${ }^{32}$

Disposable sanitary napkin use was uncommon among schoolgirls in Bangladesh and was not associated with school attendance. This finding contrasts with a similar study conducted in Ethiopia, where students 'who did not use disposable sanitary napkins were 5.4 times more likely to be absent from school than their counterparts ${ }^{17}$ but supports a recent systematic review. ${ }^{47}$ In Bangladesh, and some other settings, access to a gender-separated toilet might be a more effective intervention than provision of menstrual hygiene supplies.

Restrictions imposed by guardians were independently associated with school absence in our study. Guardians may impose such restriction due to cultural norms and stigma related to menstruation, ${ }^{26}{ }^{27}$ which should be addressed by menstrual health and education programmes. ${ }^{48}$ The issue of restrictions impacting girls' education also indicated the importance of a broader discussion on menstrual hygiene within the community.

In addition to difficulties with measuring attendance discussed above, this study has other important limitations. We identified adolescent schoolgirls who reached menarche with the help of a female teacher, and so our sample might be non-representative as teachers might have suggested including girls who have difficulty with menstruation. Conversely, those who were absent on the survey day may have been menstruating and so may have been under-represented. We did not explore the reasons behind schools keeping toilets locked from the outside or why most schools taught about menstruation after girls reach menarche because this study did not include a qualitative investigation.

\section{CONCLUSION}

In a nationally representative sample, $41 \%$ of schoolgirls in Bangladesh reported missing 16\% of school days because of menstruation. The risk factor analysis suggests several modifiable factors contributed to school absence. Although further research to assess the effectiveness of interventions to address these problems would be productive, the current data suggest that schools should ensure that toilets are open during school hours and the school curriculum should be revised in a way that menstruation is taught 3 years earlier than currently presented so that girls can learn about menstruation from female teachers before they experience menarche. A broader discussion within the community might also create a more supportive environment for girls to attend school during menstruation. Efforts are also required to develop the capacity of teachers to teach menstrual hygiene education. We recommend conducting further exploratory studies to better understand beliefs and norms about menstruation, 
use and preference of absorbents and issues related to discomfort at school and a better way to capture school attendance. We also recommend further research on the impact of gender-separated toilets and menstrual hygiene education on school attendance and girls' educational outcomes.

Acknowledgements Authors would like to thank Diana Diaz Granados and Astrid Dier for language editing and manuscript review.

Contributors MUA, SPL, AKH, MKI, AO and LU conceived and designed the original protocol. All authors except TM were involved in amending the protocol. MUA, AKH, MR and LU coordinated the study throughout. Data entry, cleaning and analysis were carried out by AKS, PKG and MUA. AKS cleaned the data and ran preliminary analysis with input from MUA, AKH, LU, MR, SPL and TM. MUA carried out advanced analysis and $A K H, L U, M R, S P L, P K G, A O, M K I$ and TM provided advice on data interpretation. MUA wrote the first draft of the manuscript with LU and AKH. All authors contributed to subsequent and final drafts.

Funding This study was funded by WaterAid Bangladesh and grant number was GR-01018. icddr,b acknowledges with gratitude the commitment of WaterAid Bangladesh to its research efforts. icddr,b is thankful to the Governments of Bangladesh, Canada, Sweden and the UK for providing core/unrestricted support.

Competing interests None declared.

Ethics approval Ethical Review Committee at icddr,b.

Provenance and peer review Not commissioned; externally peer reviewed. Data sharing statement № additional data are available.

Open Access This is an Open Access article distributed in accordance with the Creative Commons Attribution Non Commercial (CC BY-NC 4.0) license, which permits others to distribute, remix, adapt, build upon this work non-commercially, and license their derivative works on different terms, provided the original work is properly cited and the use is non-commercial. See: http://creativecommons.org/ licenses/by-nc/4.0/

(C) Article author(s) (or their employer(s) unless otherwise stated in the text of the article) 2017. All rights reserved. No commercial use is permitted unless otherwise expressly granted.

\section{REFERENCES}

1. Water Engineering and Development Centre. Developing knowledge and capacity in water and sanitation: menstruation hygiene management for schoolgirls in low-income countries, 2012. http:// wedc.lboro.ac.uk/resources/factsheets/FS007_MHM_A4_Pages.pdf

2. McMahon SA, Winch PJ, Caruso BA, et al. 'The girl with her period is the one to hang her head' Reflections on menstrual management among schoolgirls in rural Kenya. BMC Int Health Hum Rights 2011;11:7.

3. Kirk J, Sommer M. Menstruation and body awareness: linking girls' health with girls' education. Amsterdam, The Netherlands: Royal Tropical Institute (KIT), 2006:1-22.

4. United Nations, World Population Monitoring 2003. Population, education and development, in United Nations publication, 2004.

5. World Bank Group. Education Global Practice: Smarter Education Systems for Brighter Futures, 2016. http://documents.worldbank. org/curated/en/212341467999691082/pdf/98450-REVISED-PUBLICWB-EGP-Reaching-Girls-040816-final6-web.pdf.

6. Mason L, Nyothach E, Alexander K, et al. 'We keep it secret so no one should know' - a qualitative study to explore young schoolgirls attitudes and experiences with menstruation in rural western Kenya. PLoS One 2013;8:e79132.

7. Tegegne TK, Sisay MM. Menstrual hygiene management and school absenteeism among female adolescent students in Northeast Ethiopia. BMC Public Health 2014;14:1118.

8. World Health Organization. Progress on sanitation and drinkingwater-2013 update, 2013.

9. Alexander K, Oduor C, Nyothach E, et al. Water, sanitation and hygiene conditions in Kenyan rural schools: are schools meeting the needs of menstruating girls? Water 2014;6:1453-66.

10. Long J, Caruso BA, Lopez D, et al. WASH in schools empowers girls' education in rural Cochabamba, Bolivia: an assessment of menstrual hygiene management in schools. New York: United Nations Children's Fund, 2013.
11. Dambhare DG, Wagh SV, Dudhe JY. Age at menarche and menstrual cycle pattern among school adolescent girls in Central India. Glob J Health Sci 2012;4:105-11.

12. Zegeye DT, Megabiaw B, Mulu A. Age at menarche and the menstrual pattern of secondary school adolescents in northwest Ethiopia. BMC Womens Health 2009;9:29.

13. Sumpter $C$, Torondel B. A systematic review of the health and social effects of menstrual hygiene management. PLoS One 2013;8:e62004.

14. Sustainable Development Knowledge Platform. Sustainable development goals, 2015. https://sustainabledevelopment.un.org/ topics.

15. icddrb, Policy Support Unit, and WaterAid. Bangladesh National Hygiene Baseline Survey: Preliminary Report. 2014, 2014.

16. Bangladesh Bureau of Statistics, 2011. Population \& Housing Census: Preliminary Results. Dhaka, Bangladesh: Bangladesh Bureau of Statistics, 2011.

17. National Institute of Population Research and Training (NIPORT). Bangladesh Urban Health Survey. Dhaka, Bangladesh and Chapel Hill, NC, USA: NIPORT, MEASURE Evaluation, icddr,b, and ACPR, 2008.

18. icddrb. SHEWA-B WASH in school (WinS): endline assessment, 2012. Dhaka: icddr,b, 2013.

19. Dasgupta A, Sarkar M. Menstrual hygiene: how hygienic is the adolescent girl? Indian J Community Med 2008;33:77-80.

20. Oster E, Thornton R. Menstruation, sanitary products, and school attendance: evidence from a randomized evaluation. Am Econ J Appl Econ 2011;3:91-100.

21. Sommer M. Putting menstrual hygiene management on to the school water and sanitation agenda. Waterlines 2010;29:268-78.

22. WHO/UNICEF Joint Monitoring Programme (JMP) for Water Supply and Sanitation. WHO/UNICEF Joint Monitoring Programme (JMP) for Water Supply and Sanitation, 2015. http://www.wssinfo.org/ definitions-methods/watsan-categories/ (accessed 13 Jul 2015).

23. Policy Support Unit. National hygiene promotion strategy for water supply and sanitation sector in Bangladesh 2012. Dhaka: Local Government Division, 2015.

24. Caruso BA. WASH in schools empowers girls' education: tools for assessing menstrual hygiene management in schools. New York: United Nations Children's Fund, 2014.

25. Haver J, Caruso BA, Ellis A, et al; WASH in schools empowers girls' education in Masbate Province and Metro Manila, Philippines: an assessment of menstrual hygiene management in schools. New York: United Nations Children's Fund, 2013.

26. House S, Mahon T, Cavill S. Menstrual hygiene matters. London: WaterAid, 2012.

27. WaterAid. Is menstrual hygiene and management an issue for adolescent girls? A comparative study of four schools in different settings of Nepal. Nepal: WaterAid Nepal, 2009.

28. Mason L, Laserson KF, Oruko K, et al. Adolescent schoolgirls' experiences of menstrual cups and pads in rural western Kenya: a qualitative study. Waterlines 2015;34:15-30.

29. Grant MJ, Lloyd CB, Mensch BS. Menstruation and school absenteeism: evidence from rural Malawi. Comp Educ Rev 2013;57:260-84

30. Phillips-Howard PA, Nyothach E, Ter Kuile FO, et al. Menstrual cups and sanitary pads to reduce school attrition, and sexually transmitted and reproductive tract infections: a cluster randomised controlled feasibility study in rural Western Kenya. BMJ Open 2016;6:e013229.

31. Freeman MC, Greene LE, Dreibelbis R, et al. Assessing the impact of a school-based water treatment, hygiene and sanitation programme on pupil absence in Nyanza Province, Kenya: a cluster-randomized trial. Trop Med Int Health 2012;17:380-91.

32. Montgomery P, Ryus CR, Dolan CS, et al. Sanitary pad interventions for girls' education in Ghana: a pilot study. PLoS One 2012;7:48274.

33. Adukia A. Sanitation and education. Chicago: University of Chicago, 2016.

34. Birdthistle I, Dickson K, Freeman M, et al. What impact does the provision of separate toilets for girls at schools have on their primary and secondary school enrolment, attendance and completion?: a systematic review of the evidence. London: EPPI-Centre, Social Science Research Unit, Institute of Education, University of London, 2011.

35. Haque SE, Rahman M, Itsuko K, et al. The effect of a school-based educational intervention on menstrual health: an intervention study among adolescent girls in Bangladesh. BMJ Open 2014;4:e004607.

36. Mahon T, Fernandes M. Menstrual hygiene in South Asia: a neglected issue for WASH (water, sanitation and hygiene) programmes. Gender \& Development 2010;18:99-113. 
37. Sommer M, Vasquez E, Worthington N, et al. WASH in schools empowers girls' education. Proceedings of the Menstrual Hygiene Management in Schools Virtual Conference 2012. 2013.

38. Crawford M, Menger LM, Kaufman MR. 'This is a natural process': managing menstrual stigma in Nepal. Cult Health Sex 2014;16:426-39.

39. Ray Sudeshna DA. Determinants of menstrual hygiene among adolescent girls: a multivariate analysis. Natl $J$ Community Med 2012;3:294-301.

40. Joshi D, Buit G, González-Botero D. Menstrual hygiene management: education and empowerment for girls? Waterlines 2015;34:51-67.

41. Tamiru S, Mamo K, Acidria P, et al. Towards a sustainable solution for school menstrual hygiene management: cases of Ethiopia, Uganda, South-Sudan, Tanzania, and Zimbabwe. Waterlines 2015;34:92-102.

42. Trinies V, Caruso BA, Sogoré A, et al. Uncovering the challenges to menstrual hygiene management in schools in Mali. Waterlines 2015;34:31-40.
43. Naeem K, Klawitter S, Aziz A. Learning, acting, and learning (LAL) research on schools' menstrual hygiene management (MHM): Pakistan. Waterlines 2015;34:103-12.

44. Kilgour L, Matthews N, Christian P, et al. Health literacy in schools: prioritising health and well-being issues through the curriculum. Sport Educ Soc 2015;20:485-500.

45. Aniebue UU, Aniebue PN, Nwankwo TO. The impact of premenarcheal training on menstrual practices and hygiene of nigerian school girls. Pan Afr Med J 2009;2:9.

46. Das P, Baker KK, Dutta A, et al. Menstrual hygiene practices, WASH access and the risk of urogenital infection in women from Odisha, India. PLoS One 2015;10:e0130777.

47. van Eijk AM, Sivakami M, Thakkar MB, et al. Menstrual hygiene management among adolescent girls in India: a systematic review and meta-analysis. BMJ Open 2016;6:e010290.

48. Sahin M. Guest editorial: tackling the stigma and gender marginalization related to menstruation via WASH in schools programmes. Waterlines 2015;34:3-6. 